\title{
Monospecies and multispecies probiotic formulations produce different systemic and local immunostimulatory effects in the gilthead seabream (Sparus aurata L.)
}

\author{
Irene Salinas ${ }^{a, d}$, Luigi Abelli ${ }^{b}$, Fabrizio Bertoni ${ }^{b}$, Simona Picchietti ${ }^{c}$, \\ Ana Roque ${ }^{d}$, Dolors Furones ${ }^{d}$, Alberto Cuesta ${ }^{a}$, José Meseguer ${ }^{a}$, \\ Maria Ángeles Esteban ${ }^{a, *}$
}

\author{
a Fish Innate Immune System Group, Department of Cell Biology and Histology, Faculty of Biology, \\ University of Murcia, 30100 Murcia, Spain \\ ${ }^{\mathrm{b}}$ Comparative Anatomy Section, Department of Biology \& Evolution, University of Ferrara, 44100 Ferrara, Italy \\ c Department of Environmental Sciences, Tuscia University, 01100 Viterbo, Italy \\ d Pathology Group, Institut de Recerca y Tecnologia Agroalimentaries, IRTA, Ctra, Poble Nou, \\ Km 5,5 Sant Carles de la Ràita 43540 Tarragona, Spain
}

Received 21 January 2008; revised 14 March 2008; accepted 17 March 2008 Available online 26 March 2008

\author{
KEYWORDS \\ Lactobacillus \\ delbrüeckii lactis; \\ Bacillus subtilis; \\ Probiotic formulations; \\ Innate immunity; \\ Gut; \\ IgM; \\ Gilthead seabream; \\ Sparus aurata
}

\begin{abstract}
The effects of the oral administration of heat-inactivated Lactobacillus delbrüeckii ssp. lactis and Bacillus subtilis, individually or combined, on gilthead seabream immune responses were investigated both systemically and locally in the gut.

In a first experiment, seabream $(65 \mathrm{~g})$ were fed for 3 weeks different diets supplemented with $1 \times 10^{7} \mathrm{CFU} \mathrm{g}^{-1}$ Lactobacillus, $1 \times 10^{7} \mathrm{CFU} \mathrm{g}^{-1}$ Bacillus, or $0.5 \times 10^{7} \mathrm{CFU} \mathrm{g}^{-1}$ Lactobacillus plus $0.5 \times 10^{7} \mathrm{CFU} \mathrm{g}^{-1}$ Bacillus. Controls were fed non-supplemented diet. Six fish per group were sampled at the end of the trial and some humoral and cellular systemic innate immune parameters were evaluated. Feeding the mixture of the two killed bacteria species significantly increased natural complement, serum peroxidase and phagocytic activities compared with controls.

In a second experiment, juvenile seabream ( $13 \mathrm{~g})$ were fed for 3 weeks the same experimental diets and total serum $\lg M$ and numbers of gut $\lg ^{+}$cells and acidophilic granulocytes were evaluated. All these parameters were significantly higher in the multispecies probiotic group compared to monospecies and control fed groups.
\end{abstract}

\footnotetext{
* Corresponding author. Tel.: +34 968367965; fax: +34 968363963.

E-mail address: aesteban@um.es (M.Á. Esteban).
} 